\title{
End-Stage Dementia: Aminoff Suffering Syndrome and Relief of Suffering Units
}

\author{
Bechor Z. Aminoff* \\ Geriatric Division, The Chaim Sheba Medical Center, Tel Hashomer, and Human Suffering and Satisfaction Research \\ Center, El-Ad, Israel
}

\begin{abstract}
Aminoff suffering syndrome (ASS) in advanced dementia is the new proposed term for a pathological symptomatology and entity that is characterized by a high Mini Suffering State Examination (MSSE) scale score, <6 months survival, irreversible and intractable aggravation of suffering and medical condition until demise.
\end{abstract}

\begin{abstract}
This paper proffers a new, alternative approach and setting for end-stage dementia (ESD) patients with ASS that could pertain to the Israeli setting, and could possibly also be applicable in other countries. Short hospitalization periods of approximately 1 month, and treatment in Relief of Suffering Units may be a new, palliative approach and present a possible solution for coping with the horrendous burden of the anguish of end-of-life dementia patients, their families, and the medical and nursing staff.
\end{abstract}

Keywords: End-stage dementia, Aminoff suffering syndrome, relief of suffering units.

\section{INTRODUCTION}

Alzheimer's disease is the seventh leading cause of all deaths in the United States, and the fifth leading cause of death in Americans older than 65 years of age. More than 5 million Americans are estimated to have Alzheimer's disease [1].

The course of Alzheimer's disease is prolonged. End-stage dementia (ESD) patients are completely helpless, confined to wheelchairs or bedridden, with double incontinence, malnutrition, feeding tubes, decubitus ulcers and suffering that may continue for months or years [2]. It is at this juncture that the illness is defined as end-stage (stage seven or beyond according to the Functional Assessment Staging Scale) [3], despite the extended life expectancy.

The treatment of an ESD patient with a high level of comorbidity and severe disability may be far more difficult than treatment of a patient with end-stage heart or lung disease, or cancer. The difficulty lies in the complexity of the medical, nursing, cognitive, emotional, ethical, religious and social problems. Treatment is lengthy and exhausts medical and nursing staff, as well as families. Despite intensive efforts by the medical staff, the patient's condition deteriorates, the level of suffering increases [4], and often the process seems endless.

Medical and nursing staffs are expected to diagnose symptoms and syndromes of diseases, but not necessarily to be aware of the suffering of the patient [5]. Alleviation of suffering is a fundamental goal of medicine, especially at the end-oflife [6]. The alleviation of suffering is a central goal of palliative care, but little research has addressed the construct of suffering as a global experience of the whole person [7].

\footnotetext{
*Address correspondence to this author at the Geriatric Division, The Chaim Sheba Medical Center, Tel Hashomer 52621, Israel; and Human Suffering and Satisfaction Research Center, Shamay 26, El-Ad 40800, Israel; Tel: +972-52-6666550; Fax: +972-3-9360126;

E-mail: bechorz@yahoo.com
}

This may undermine the caregiver's ability to accurately assess the patient's needs. Various aspects of end-of-life for patients with advanced dementia have been discussed, yet issues of suffering and appropriate health care for such patients remain controversial [8].

Many hospitalized patients suffer from substandard quality-of-life due to cognitive and functional impairment, and other mental and social problems, but they cannot be defined as dying patients. A definition of an end-stage patient according to the level of suffering would greatly advance medical science in its entirety, as to date in the majority of medical text books, or medical practice, there is no classification for "suffering", despite daily use of the word by medical staff and families of patients.

Medical personnel and society in general, are unaware that there are no tools with which to measure and diagnose the level of suffering of a dying patient. Similarly, there are also no tools available to estimate the 6-month survival period of terminal dementia patients.

The nature of suffering makes it difficult to assess, and to the best of our knowledge, there have been no reports in the medical literature on methods of examining the level of suffering. This is in contrast to various clinical instruments designed to measure quality-of-life or satisfaction with care at the endof-life [9].

Moreover, the suffering of ESD patients is often accompanied by an inability to verbally indicate the extent of their misery. We endeavored to approach this issue from a more objective, rather than the classic and immeasurable subjective approach. Some may argue that establishing a clinical diagnosis of suffering is impossible, yet others feel that ESD represents a "persistent vegetative state" without sensation, perception and emotion.

However, it is most unlikely that the association between subjective suffering and objective clinical tools is identical for 
end-of-life dementia patients, and for those with a less advanced stage of disease. We firmly believe that despite severe cognitive impairment, sensation and emotional status of these patients are only partially impaired, in which case probability of suffering is considerable. Objective, well-validated tools should be used to evaluate the suffering level.

\section{MINI SUFFERING STATE EXAMINATION (MSSE)}

Our recently developed Mini-Suffering-State-Examination (MSSE) scale (Table 1) [10] is the first objective clinical tool for evaluation of suffering level in ESD. The results of clinical experience with this scale were presented at world and regional congresses in Berlin (1999), Jerusalem (2000), Vancouver (2001), Stockholm (2002), Tokyo (2003), Las Vegas (2004), Rio-de-Janeiro (2005), Madrid (2006), SaintPetersburg (2007) and Trondheim (2008), and in our book "Measurement of Suffering in End-Stage Alzheimer's Disease" [2].

Table 1. Mini Suffering State Examination (MSSE)

\begin{tabular}{|c|c|c|}
\hline & Items of MSSE & YES - 1 \\
\hline 1 & Not calm & \\
\hline 2 & Screams & \\
\hline 3 & Pain & \\
\hline 4 & Decubitus ulcers & \\
\hline 5 & Malnutrition & \\
\hline 6 & Eating disorders & \\
\hline 7 & Invasive action & \\
\hline 8 & Unstable medical condition & \\
\hline 9 & Suffering according to medical opinion & \\
\hline \multirow[t]{2}{*}{10} & Suffering according to family opinion & \\
\hline & MSSE score & \\
\hline $\begin{array}{l}\text { The MS } \\
\text { Low lev } \\
\text { Interme } \\
\text { High le }\end{array}$ & $\begin{array}{ll}\text { scale score Interpretation: } & \\
\text { of suffering } & 0-3 \\
\text { te level of suffering } & 4-6 \\
\text { of suffering } & 7-10\end{array}$ & \\
\hline
\end{tabular}

The MSSE scale is available in English, Hebrew and Dutch, and the translation and validation of a Spanish version is in progress.

The MSSE scale comprises 10 items relating to the patients' characteristics, as well as the perception of their condition by medical staff and families. Each item scores 0 (no) or 1 (yes). Total score ranges between 0-10, with high scores reflecting higher degrees of suffering.

The MSSE is brief and it takes the physician or nurse less than 10 minutes to evaluate the suffering level of the patient. The significant reliability of the MSSE scale was demonstrated by using the Cronbach- $\alpha$ model (0.798). Concurrent validity of the MSSE scale was proven by Pearson correlation with the Symptom Management with End-of-Life in Dementia (SM-EOLD) scale $(\mathrm{r}=0.574, P<0.0001)$, and the Comfort Assessment in Dying with Dementia (CAD-EOLD) scale [11], $(\mathrm{r}=-0.796, P<0.0001)$.

The mean survival of ESD patients with a low MSSE scale score $(\mathrm{MSSE}=2.24 \pm 0.99)$ was $57.76 \pm 9.73$ days, and with a median MSSE scale score $(\mathrm{MSSE}=4.92 \pm 0.83)$ the mean survival was $44.70 \pm 5.99$ days. In the high MSSE scale score group (MSSE $=8.06 \pm 1.00)$ mean survival was much shorter (27.54 \pm 4.16 days).

The differences between the survival times of the three MSSE scale score groups was evaluated by Kaplan-Meier analysis (Log Rank, $p=0.0018$, Breslow, $(p=0.0027)$ and were significant [12].

The results of the Cox proportional Hazard model of survival showed a strong correlation between high MSSE scale score and high risk of mortality and short survival of ESD patients during the last 6 months of life $(p=0.013)$ [13].

According to the MSSE scale, it has been confirmed that ESD patients represent a heterogeneous group and have different levels of suffering. The results of our research showed that care in the geriatric department fails to decrease the high suffering level of ESD patients. The total score of MSSE scale on the day of admission was $5.62 \pm 2.31$, and increased to 6.89 \pm 1.95 on the last day of life with a significant difference $(\mathrm{p}<0.0001)$. Despite traditional medical and nursing care, a large proportion of dying dementia patients experience increased suffering as they approach death [14].

\section{AMINOFF SUFFERING SYNDROME (ASS)}

Our results on the interrelation of high MSSE scores with shorter survival period and, irreversible and intractable aggravation of suffering and medical condition until demise was defined by us as a new pathological entity in ESD, i.e. Aminoff Suffering Syndrome (ASS).

Aminoff Suffering Syndrome in advanced dementia is characterized by a high MSSE scale score, <6 months' survival, irreversible and intractable aggravation of suffering and actively dying medical condition until demise [15].

Results of our research studies and clinical experience permits us to suggest that diagnosis of ASS could serve as a key criterion for screening in general hospital wards, nursing homes, and communities for those ESD patients with high suffering levels and shorter survival periods.

\section{RELIEF OF SUFFERING UNITS}

Medicine today facilitates extended longevity at a high price of suffering to the patients, their families [16], and even to medical and caregiver staff [17].

It is easy to calculate the daily and annual costs of hospitalization of ESD patients. The maintenance costs of long hospitalization are enormous over such an extended period. In the future, with increasing successes in the treatment of heart disease and tumors, dementia patients may well be in the majority in hospital departments. Medical practitioners, politicians, and society as a whole, should develop new medical indications for short hospitalization of ESD patients. Actively dying in conditions which we defined as ASS in ESD could be a new criterion for short hospitalization.

The life expectancy of patients with a low level of suffering is generally long. It is unnecessary to transfer them from their private homes, nursing homes, or hospital departments for treatment within a special framework.

Conversely, the life expectancy of ESD patients with a high suffering level is short. The high MSSE score may pre- 
dict the last month of life in ESD. End-stage dementia patients with a high suffering level no longer respond to treatment and could be defined as terminal, as in the "point of no return".

It is accepted that patients with end-stage cancer be treated in hospices. There is a significant difference between patients with end-stage cancer and those with ESD [18]. Most cancer patients are lucid until their actual demise; some are mobile and can eat independently. The life expectancy of patients with end-stage cancer is short, and they themselves can often decide which treatment they wish to receive and sanction their hospitalization in a hospice.

Only a small minority of noncancer patients have access to specialist palliative care services, which stems, partially, from differences in both enrollment criteria and financial coverage in various countries, in particular between the United Kingdom and the United States. When St. Christopher's hospice was first opened, it was envisaged that this service would be accessible to non-cancer patients, including those with dementia, yet, cancer patients remained the dominant diagnosis group [19].

The scenario of ESD patients is completely different. We do not refer to a few hundred patients, but to thousands with advanced dementia, who are hospitalized in internal medicine, surgical, orthopedic and geriatric departments, and innumerable patients with severe dementia who reside in nursing homes and in their own homes [20]. A palliative care model for patients with dementia is more complex compared with that adopted for cancer patients [21].

In Western countries dementia patients are eligible for hospice care, but in fact, only $1.5 \%$ of ESD patients in the United States have the privilege of admission and treatment in hospices [22]. Provision of palliative care support for the elderly with nonmalignant diseases is often inadequate [23].

Currently, most individuals with dementia die in intensive care wards of hospitals, where staff is ineptly trained to recognize and address their special needs [24]. Dementia patients, who die in such wards, are deprived of access to palliative care [25]. There is certainly a moral imperative behind the idea that end-of-life care for individuals with dementia should be improved [26]. Hughes and colleagues [27] have called for the development of specialist palliative care teams for dementia patients.

The criterion of a life expectancy $<6$ months for enrolling non-oncology patients to a hospice was established by the United States Government as part of the Medicare Hospice Benefit in 1982 [28].

Several studies have investigated the 6-month survival of persons with a primary diagnosis of advanced dementia [29]. The National Hospice Organization eligibility guidelines for patients with dementia are based primarily on the Functional Assessment Staging (FAST) criteria [3], which have been heavily criticized. A study on Dutch patients [30] has also suggested that the Hospice Medicare Guidelines are not valid for predicting survival in late dementia. More recently, a risk score based on 12 variables from the Minimal Data Set proposed more accurate estimates of 6-month mortality for nursing home residents suffering from advanced dementia than existing prognostic guidelines [31].

The principles of treatment of dementia patients in hospices is based on palliative medicine only, which in some hospices implies refraining from the use of feeding tubes or gastrostoma, the use of antibiotics and active medical treatment of the patient [32].

For religious patients, the sanctity of life is paramount, and human life is deemed to be of infinitive value [33], but Judaism recognizes that all life is finite and, as such, its teachings are compatible with the principles of palliative medicine and endof-life care as they are currently practiced [34]. According to religious laws, only supportive treatment may be administered to a dying patient who is in agony. No definite decisions and clear-cut directives have been coordinated by medical and religious orders. Therefore, almost every patient who delivers his soul to the Almighty within the confines of a hospital is on a path of excruciating and needless suffering.

Very few hospital departments exist that really succeed in coping with ESD patients with a high level of suffering, or have the capability to enable them to die with a low level of suffering. Some treatment regimes of such patients are inadequate, unnecessary and sometimes futile, and do not contribute to reducing the level of suffering [35]. Unjustified medical operations are an additional source of distress.

The high, intractable suffering level of ESD patients should be a principal criterion for enrolling these patients in a hospice, or high level of suffering unit. The avoidance of suffering is the only justification to shorten the life of the sufferer, provided that the acts performed do not fall within the religious definition of murder, namely active and direct action that curtails life [36]. In our view, due to the inability of existing hospital departments to diminish the high level of suffering in end-stage patients, we propose the establishment of special units for those patients with a 1-month life expectancy.

Aminoff Suffering Syndrome was proposed as the key criterion for enrolling end-stage disease and dying patients to a hospice, or Relief of High Suffering with Dementia Units [37]. The only criteria for hospitalization in such a unit would be the high level of suffering, diagnosed by an objective method to estimate the suffering of an ESD patient.

The indication for hospitalization in the unit is neither the cognitive, functional and nutritional condition, nor any other medical problem, but intensive care to reduce the suffering level of the ESD patient. Treatment in the unit does not imply euthanasia.

Relief of suffering units could be part of intensive care units in internal medicine, surgery, geriatric or other conventional wards. The decision-making process, evaluation of the patient's suffering level, and diagnosis of irreversible medical condition, should change the approach from "intensive" futile care for actively dying patients to intensive care to diminish their suffering. We hope that in the future new treatment approaches will be developed to diminish suffering in ESD.

The aforementioned may comprise intensified nursing and qualified medical staff in order to control the patients' suffering, and that of their families. The aim of the Relief of Suffering with Dementia Units is to treat patients with high levels of suffering, to support them until their last breath and allow them to die with dignity.

Should there be an improvement in the patients' condition during hospitalization in the unit, and their level of suffering diminishes, they may be discharged from the unit and trans- 
ferred to a regular geriatric department, nursing home, or to their own homes.

The estimated hospitalization period in the Relief of Suffering with Dementia Units is approximately 1 month. These units would be the source for integral medical, nursing, religious, ethical, psychological and sociological research, seeking methods to cope with the horrendous burden of suffering of ESD patients, their families and the nursing staff.

\section{CONCLUSIONS}

1. Screening the suffering level of ESD patients by means of the MSSE scale for identifying patients with ASS;

2 Patients with ASS (MSSE = 7-10) should be hospitalized in Relief of Suffering Units;

3. Hospitalization time in such a unit is estimated to be 1 month;

4. Patients whose suffering level diminishes during hospitalization in these units could be discharged;

5. The desirable approach to ESD patients in Relief of Suffering Units should be to seek solutions to diminish the high suffering level of the patients.

\section{ABBREVIATIONS}

$\begin{array}{ll}\text { ASS } & =\text { Aminoff suffering syndrome } \\ \text { ESD } & =\text { End-stage dementia } \\ \text { MSSE } & =\text { Mini Suffering State Examination }\end{array}$

\section{REFERENCES}

[1] Alzheimer's Association. Alzheimer disease facts and figures. Alzheimer's Dement 2008; 2: 110-33.

[2] Aminoff BZ. Measurement of suffering in end-stage Alzheimer's disease. 1st ed. Tel-Aviv: Probook, Dyonon, 2007.

[3] Reisberg B. Functional Assessment Staging (FAST). Psychopharmacol Bull 1988; 24: 653-9.

[4] Aminoff BZ, Adunsky A. Dying dementia patients: Too much suffering, too little palliation. Am J Alzheimers Dis Other Demen 2004; 19: 243-47.

[5] Cassell EJ. The nature of suffering and the goals of medicine. N Engl J Med 1982; 306: 639-45.

[6] Abraham A, Kutner JS, Beaty B. Suffering at the end of life in the setting of low physical symptom distress. J Palliat Med 2006; 9: 65865.

[7] Wilson KG, Chochinov HM, McPherson CJ, et al. Suffering with advanced cancer. J Clin Oncol 2007; 25:1691-97.

[8] Hurley AC, Volicer L, Blasi ZV. End-of-life care for patients with advanced dementia. JAMA 2000; 284: 2449-50.

[9] Kiely DK, Volicer L, Teno J, Jones RN, Prigerson HG, Mitchell SL. The validity and reliability of scales for the evaluation of end-of-life care in advanced dementia. Alzheimer Dis Assoc Disord 2006; 20: 176-81.

[10] Aminoff BZ, Purits E, Noy Sh, Adunsky A. Measuring the suffering of end-stage dementia: Reliability and validity of the Mini Suffering State Examination. Arch Gerontol Geriatr 2004; 38: 123-30.

[11] Volicer L, Hurley CA, Blasi VZ. Scales for evaluation of end-of-life care in dementia. Alzheimer Dis Assoc Disord 2001; 15: 194-200.

[12] Aminoff BZ. Mini-Suffering State Examination Scale: possible key criterion for 6 months' survival and mortality of critically ill dementia patients. Am J Hosp Palliat Med 2008; 24: 470-4.
[13] Aminoff BZ, Adunsky A. Their last six months of life: suffering and survival of end-stage dementia patients. Age Ageing 2006; 36: 597601.

[14] Aminoff BZ, Adunsky A. Dying dementia patients: Too much suffering, too little palliation. Am J Hosp Palliat Med 2005; 22: 344-8.

[15] Aminoff BZ. Aminoff Suffering Syndrome: a new pathological entity in end-stage dementia. 10th International Conference on Alzheimer's Disease and Related Disorders; 2006 July 15-20, Madrid, Spain. In: Alzheimer's disease: New advances. Medimond International Proceedings. Bologna, Italy 2007; 55-9.

[16] Aminoff BZ. Overprotection phenomenon with dying dementia patients. Am J Hosp Palliat Med 2005; 22: 247-8.

[17] Schulz R, McGinnis AK, Zhang S, et al. Dementia patient suffering and caregiver depression. Alzheimer Dis Assoc Disord 2008; 22: $170-6$.

[18] Jaul E, Rosin A. Planning care for non oncology terminal illness in advanced age. Isr Med Assoc J 2005; 7: 5-8.

[19] Doyle D, Hanks G, Cherny N, Calman K. Oxford textbook of palliative medicine. Palliative medicine in non-malignant diseases. 3rd ed. Oxford: Oxford University Press, 2004; 843-7.

[20] Friedmann R, Sonnenblick M. The who and where of care: Nononcology terminal illness in the elderly. Isr Med Assoc J 2005; 7: 940.

[21] Rozzini R, SabatiniT, Ranhoff A, Trabucchi M. Do we really need palliative care for severe dementia patients? Age Ageing 2007; 36: 584-7.

[22] Christakis NA, Escarce JJ. Survival of Medi-care patients after enrollment in hospice programs. N Engl J Med 1996; 335: 172-8.

[23] Dainty P, Leung D. An evaluation of palliative care in the acute geriatric setting. Age Ageing 2008; 37: 327-30.

[24] Bayer A. Death with dementia-the need for better care. Age Ageing 2006; 35: 101-2.

[25] Sampson LE, Gould V, Lee D, Blanchard RM. Differences in care received by patients with and without dementia who died during acute hospital admission: a retrospective case note study. Age Ageing 2006; 35: 187-9.

[26] Hughes JC, Jolley D, Jordan A, Sampson EL. Palliative care in dementia: issues and evidence. Advan Psychiatr Treat 2007; 13: 251-60.

[27] Hughes JC, Robinson L, Volicer L. Specialist palliative care in dementia. BMJ 2005; 330: 57-8.

[28] Standards and Accreditation Committee: Medical Guidelines Task Force of the National Hospice Organization. Medical guidelines for determining prognosis in selected non-cancer diseases, $2^{\text {nd }}$ ed. Arlington, Virginia:National Hospice Organization, 1996.

[29] Doberman JD, Yasar S, Durso CS. Would you refer this patient to hospice? An evaluation of tools for determining life expectancy in end-stage dementia. J Palliat Med 2007; 10: 1410-9.

[30] Koopmans RT, Ekkerink JL, Van Weel C. Survival to late dementia in Dutch Nursing Home Patients. J Am Geriatr Soc 2003; 51: 184-7.

[31] Mitchell SL, Kiely DK, Hamel MB, Park PS, Morris JN, Fries BE. Estimating prognosis for nursing home residents with advanced dementia. JAMA 2004; 291: 2734-40.

[32] Volicer L. Management of severe Alzheimer's disease and end-of-life issues. Clin Geriat Med 2001; 17: 377-91.

[33] Clarfield AM, Gordon M, Maxwell M. Ethical issues in end-of-life geriatric care: The approach of three monotheistic religions - Judaism, Catholicism and Islam. J Am Geriatr Soc 2003; 51: 1149-54.

[34] Kinzbrunner B. Jewish medical ethics and end-of-life care. J Palliat Med 2004; 7: 558-73.

[35] Lynn J, Goldstein E. Advanced care planning for fatal chronic illness: avoiding common place errors and unwanted suffering. Ann Intern Med 2003; 138: 812-3.

[36] Barilan JM. The terminal patient: Jewish religious law, the Steinberg Report and the bioethical discourse in Israel. Harefuah 2003; 142: 558-62.

[37] Aminoff BZ. The New Israeli Law "The dying patient" and Relief of Suffering Units. Am J Hosp Palliat Med 2007; 24: 54-8. 